\title{
Efeitos da temperatura de armazenamento de grãos de arroz integral de pericarpo pardo, preto e vermelho sobre as propriedades físico-químicas e de pasta
}

\author{
Effects of storage temperature of whole rice grains with brown, black and red \\ pericarps, on the physicochemical and pasting properties
}

\section{Valmor Ziegler ${ }^{1 *}$, Cristiano Dietrich Ferreira', Lenara Tonieto', Juciano Gabriel da Silva', Maurício de Oliveira1, Moacir Cardoso Elias ${ }^{1}$}

${ }^{1}$ Universidade Federal de Pelotas (UFPEL), Departamento de Ciência e Tecnologia Agroindustrial (DCTA), Pelotas/RS - Brasil

\section{*Corresponding Author}

Valmor Ziegler, Universidade Federal de Pelotas (UFPEL), Departamento de Ciência e Tecnologia Agroindustrial (DCTA), Rua Gomes Carneiro, 1671, apartamento 301, Centro, CEP: 96010-610,Pelotas/RS - Brasil, e-mail: vamgler@hotmail.com

Cite as: Effects of storage temperature of whole rice grains with brown, black and red pericarps, on the physicochemical and pasting properties. Braz. J. Food Technol., v. 20, e2016051, 2017

\section{Resumo}

O arroz (integral com pericarpo pardo, preto e vermelho, polido, parboilizado integral e parboilizado polido) é base da dieta alimentar nos países em desenvolvimento e serve como veículo para vitaminas e minerais. $O$ armazenamento é uma etapa imprescindível, na qual se busca a manutenção da qualidade dos grãos até serem industrializados e consumidos, sendo a temperatura de armazenamento um dos principais fatores que causam alterações durante esse período. Com isso, o objetivo do estudo foi avaliar os efeitos do tempo (seis meses) e da temperatura (16, 24, 32 e $40{ }^{\circ} \mathrm{C}$ ) de armazenamento de grãos de arroz integral de pericarpo pardo, preto e vermelho sobre a composição proximal, as propriedades de pasta, as proteínas solúveis, o pH dos grãos e a condutividade elétrica. Após seis meses de armazenamento, houve aumento da temperatura de pasta e da condutividade elétrica, com redução do $\mathrm{pH}$ e da solubilidade proteica, principalmente no armazenamento a $40^{\circ} \mathrm{C}$. O armazenamento de grãos de arroz com pericarpo pardo, preto e vermelho, na temperatura de $16{ }^{\circ} \mathrm{C}$, é o mais indicado para a redução da atividade metabólica e enzimática, proporcionando as mínimas alterações nas propriedades físico-químicas e de pasta.

Palavras-chave: Arroz pigmentado; Conservação; Reações químicas.

\section{Abstract}

Rice (whole with brown, black and red pericarps, polished, whole parboiled and polished parboiled) is the staple diet in developing countries and serves as a vehicle for vitamins and minerals. Storage is an essential step, aiming to maintain the quality of the grains until they are industrialized and consumed, and storage temperature is one of the main factors causing changes during this period. Thus the objective of the present study was to evaluate the effects of storage time (6 months) and temperature $\left(16,24,32\right.$ and $\left.40^{\circ} \mathrm{C}\right)$ of whole grain rice with brown, black and red pericarps on the proximate composition, the pasting properties, the soluble proteins, the $\mathrm{pH}$ values and the electrical conductivities of the grains. After six months storage there were increases in the pasting temperatures and electrical conductivities with reductions in the $\mathrm{pH}$ and protein solubility values, mainly for storage at $40^{\circ} \mathrm{C}$. The storage of rice grains with brown, black and red pericarps at $16{ }^{\circ} \mathrm{C}$ is the temperature most indicated for the reduction of their metabolic and enzymatic activities, providing the minimal changes in the physicochemical and pasting properties.

Keywords: Pigmented rice; Conservation; Chemical reactions. 
Efeitos da temperatura de armazenamento de grãos de arroz integral de pericarpo pardo, preto e vermelho sobre as propriedades físico-químicas e de pasta

Ziegler, V. et al.

\section{Introdução}

O arroz (integral com pericarpo pardo, preto e vermelho, polido, parboilizado integral e parboilizado polido) (Oryza sativa L.) é a principal fonte energética para cerca de dois terços da população mundial (ELIAS et al., 2012). Nos países em desenvolvimento, o arroz serve como base da dieta alimentar e como veículo para vitaminas, principalmente do complexo B, e minerais (HEINEMANN et al., 2005), sendo cada vez mais popular pelas suas propriedades nutricionais benéficas para a saúde (GUNARATNE et al., 2013; WEl et al., 2007). O Brasil é o nono maior produtor mundial, com 12,4 milhões de toneladas produzidas na safra de 2014/2015 (CONAB, 2015). O arroz pigmentado (pericarpo preto ou vermelho) representa de 2 a $3 \%$ desta produção e o seu consumo vem ganhando importância devido às suas propriedades nutracêuticas e bioativas (SOMPONG et al., 2011; FINOCCHIARO et al., 2010), atendendo a nichos específicos de mercado.

A colheita dos grãos de arroz ocorre sazonalmente durante o ano, o que torna as etapas de pós-colheita importantes e determinantes para a manutenção da qualidade dos grãos e também para suprir a demanda das indústrias de processamento desses grãos. Durante o armazenamento dos grãos, que são tecidos vivos, os principais fatores que interferem na qualidade são a temperatura, a umidade dos grãos e a umidade relativa do ambiente de armazenamento, fatores estes que desencadeiam uma série de reações físico-químicas, bioquímicas e metabólicas dos grãos, pelas quais as reservas energéticas armazenadas nos tecidos de sustentação são desdobradas, transportadas e ressintetizadas no eixo embrionário (AGUIAR et al., 2012; PEREZ-GARCIA; GONZALEZ-BENITO, 2006; SANTOS et al., 2004).

Alguns estudos avaliando o armazenamento de grãos de arroz em diferentes condições vêm sendo realizados. Park et al. (2012) investigaram as mudanças nas características físico-químicas do arroz de pericarpo pardo polido armazenado nas temperaturas de $4,20,30$ e $40^{\circ} \mathrm{C}$, e verificaram aumento na acidez lipídica e no valor da cromaticidade b* (coloração amarela), com redução no teor de água e na brancura, além de alterações nas propriedades de pasta, texturométricas e sensoriais de arroz cozido, principalmente no armazenamento a $40^{\circ} \mathrm{C}$. Ziegler et al. (2016) investigaram os efeitos da temperatura de armazenamento sobre as propriedades tecnológicas e sensoriais de arroz integral de pericarpo pardo, preto e vermelho, e verificaram que o armazenamento dos grãos de arroz integral na faixa de temperatura entre 16 e $24^{\circ} \mathrm{C}$ é o que proporciona as menores alterações no teor de grãos manchados, ardidos e amarelos, nos rendimentos gravimétrico e volumétrico, no perfil colorimétrico e nos atributos sensoriais. Zhou et al. (2014) estudaram o armazenamento de arroz de pericarpo pardo e preto integrais, armazenados nas temperaturas de 4 e $37^{\circ} \mathrm{C}$, e verificaram uma redução de compostos fenólicos solúveis e insolúveis, e da atividade antioxidante no armazenamento a $37^{\circ} \mathrm{C}$, após seis meses.

Embora algumas pesquisas já tenham sido realizadas com armazenamento de grãos de arroz, estudos com armazenamento de arroz integral com pericarpo preto e vermelho, sobre as propriedades físico-químicas e de pasta, ainda são necessários. Dessa forma, objetivou-se, com o estudo, avaliar os efeitos do tempo (seis meses) e da temperatura $\left(16,24,32\right.$ e $40^{\circ} \mathrm{C}$ ) de armazenamento de grãos de arroz integral de pericarpo pardo, preto e vermelho sobre a composição proximal, as propriedades de pasta, as proteínas solúveis, o pH dos grãos e a condutividade elétrica.

\section{Material e métodos}

\subsection{Material vegetal e armazenamento das amostras}

As cultivares de arroz de pericarpo pardo IRGA 417 (ciclo de 115 dias), preto IAC-600 (ciclo de 110 dias) e da linhagem de arroz vermelho MPB-10 (ciclo aproximado de 110 dias) foram cultivadas em lavoura comercial, que utilizava sistema irrigado, no município de Jaguarão (Latitude: $32^{\circ} 33^{\prime} 37^{\prime \prime}$ Sul, Longitude: 5322' 52" Oeste e altitude de 23 metros), Rio Grande do Sul, Brasil. O manejo de cultivo utilizado seguiu os padrões técnicos da região onde foi cultivado. O plantio foi realizado no mês de novembro de 2014 e a colheita, no mês de março de 2015. Os grãos de arroz (dois sacos de cada coloração de pericarpo) foram colhidos com conteúdo de umidade aproximada de 20\% e transportados para o Laboratório de Pós-colheita, Industrialização e Qualidade de Grãos (Labgrãos) da Universidade Federal de Pelotas, onde foi submetido às etapas de limpeza e secagem até umidade de $13 \%$. A secagem foi realizada em secador estacionário, protótipo do Labgrãos, havendo monitoramento da temperatura da massa de grãos, para que não ultrapassasse $35^{\circ} \mathrm{C}$. Posteriormente, os grãos foram expurgados com fosfina, para evitar a interferência de insetos durante o experimento. Em seguida, a amostra foi quarteada até obter a alíquota necessária para o armazenamento. Após o quarteamento, os grãos foram descascados em equipamento Zaccaria (Type PAZ-1-DTA, Zaccaria, Brasil), sendo retirados os marinheiros (grãos que permaneceram em casca após o descascamento) e acondicionados em sacos de polietileno de baixa densidade, com 0,2 $\mathrm{mm}$ de espessura e capacidade de $0,9 \mathrm{~kg}$; foram então armazenados em câmaras BODs com temperaturas monitoradas em $16,24,32$ e $40^{\circ} \mathrm{C}$, com três repetições, durante seis meses. As embalagens, contendo os grãos, foram cobertas com papel alumínio para bloquear a luz. A cada dois meses, os sacos foram abertos para coleta de amostras e troca do ar no ambiente de armazenamento, caracterizando um sistema semi-hermético de armazenamento. Após cada coleta, as amostras foram moídas em moinho laboratorial 
Efeitos da temperatura de armazenamento de grãos de arroz integral de pericarpo pardo, preto e vermelho sobre as propriedades físico-químicas e de pasta

Ziegler, $V$. et al.

(Perten 3100, Perten Instruments, Huddinge, Sweden) para redução das partículas para 35 mesh. As amostras moídas foram utilizadas para a realização das análises descritas a seguir, com exceção da análise da condutividade elétrica, que foi realizada nos grãos inteiros.

\subsection{Análises}

\subsubsection{Composição proximal}

O teor de umidade foi determinado em estufa a $105 \pm 3^{\circ} \mathrm{C}$, com circulação natural de ar por 24 horas, de acordo com o método recomendado pela American Society of Agricultural Engineers (ASAE, 2000). O conteúdo de umidade foi expresso em percentagem (\%). O conteúdo de nitrogênio foi determinado usando o método 46-13 da American Association of Cereal Chemistry (AACC, 1995) e o conteúdo de proteína foi determinado usando o fator de conversão do nitrogênio de 5,95. O conteúdo de lipídios foi determinado usando o método 30-20 da AACC (1995). O conteúdo de cinzas foi determinado usando o método 08-01 da AACC (1995). O conteúdo de carboidratos foi determinado por diferença dos demais constituintes. Os resultados foram expressos em percentual (\%) em base seca.

\subsubsection{Propriedades de pasta}

As características viscoamilográficas dos grãos moídos foram avaliadas com o analisador rápido de viscosidade (RVA - Rapid Visco Analyser), usando programa Thermocline for Windows versão 1.10. O perfil utilizado foi o Standard Analysis 1. Colocou-se o arroz moído (5 g corrigidas para 14\% de umidade) diretamente no recipiente do RVA e adicionaram-se $25 \mathrm{~mL}$ de água destilada. A amostra foi mantida a $50{ }^{\circ} \mathrm{C}$ durante $1 \mathrm{~min}$, aquecida a $95^{\circ} \mathrm{C}$ em 3,5 min e depois mantida a $95^{\circ} \mathrm{C}$ durante 2,5 min. Em seguida, a amostra foi arrefecida até $50{ }^{\circ} \mathrm{C}$ em 4 min e depois mantida a $50{ }^{\circ} \mathrm{C}$ durante $1 \mathrm{~min}$. A velocidade de agitação foi mantida a 960 rpm durante dez segundos e depois foi mantida a 160 rpm durante 0 tempo restante de análise (Singh et al., 2004).

\subsubsection{Proteína solúvel}

O teor de proteína solúvel foi determinado segundo método descrito por Liu et al. (1992), com modificações. Em cada amostra de $2 \mathrm{~g}$, foram adicionados $50 \mathrm{~mL}$ de água destilada, sendo as amostras e a água misturadas com o auxílio de agitador magnético durante $1 \mathrm{~h}$, sendo, em seguida, centrifugadas a $5300 \times$ g durante 20 min a $24{ }^{\circ} \mathrm{C}$, em centrífuga Eppendorf Centrifuge 5430R. Uma alíquota de $1 \mathrm{~mL}$ do sobrenadante foi coletada, sendo então determinado o teor de proteína bruta na amostra pelo método Kjeldahl (AACC, 1995). A proteína solúvel foi calculada com base no percentual (\%) de proteína bruta das amostras e expressa em percentual (\%) de proteína solúvel.

\subsubsection{O pH dos grãos}

$\mathrm{O}$ pH dos grãos foi determinado segundo método proposto por Rehman et al. (2002). Uma alíquota de $2 \mathrm{~g}$ de amostra foi homogeneizada com $20 \mathrm{~mL}$ de água destilada, em vórtex por 1 min; em seguida, a solução foi filtrada e realizou-se a leitura do $\mathrm{pH}$ utilizando um pHmetro com eletrodo de vidro (Pye Unicam, Inglaterra).

\subsubsection{Condutividade elétrica}

A condutividade elétrica da água de hidratação foi determinada segundo metodologia do International Seed Testing Association (ISTA, 2008). Foram pesados $10 \mathrm{~g}$ de grãos, imersos em $75 \mathrm{~mL}$ de água deionizada (em Becker de $250 \mathrm{~mL}$ ) e incubados durante 24 h. As soluções foram agitadas suavemente e a condutividade elétrica foi determinada com condutivímetro sem filtragem da solução. Os resultados foram expressos em $\mu \mathrm{S} . \mathrm{cm}^{-1} \cdot \mathrm{g}^{-1}$.

\subsubsection{Análise estatística}

Todas as análises foram realizadas com três repetições e os resultados obtidos foram submetidos à análise estatística com o uso do programa SAS (Statistical Analysis System), com análise de variância ANOVA, seguida de comparação de médias pelo teste de Tukey a $5 \%$ de probabilidade $(p<0,05)$.

\section{Resultados e discussões}

\subsection{Composição proximal}

Os resultados obtidos para a composição proximal dos grãos de arroz de pericarpo pardo, preto e vermelho estão apresentados na Tabela 1. A composição proximal encontrada em nosso estudo está de acordo com o encontrado por Sompong et al. (2011), Monks et al. (2013) e Paiva et al. (2014) em grãos de arroz com pericarpo pardo e pigmentado.

Após seis meses de armazenamento, não são observadas alterações ( $p>0,05)$ no conteúdo de proteínas, lipídios e cinzas. No entanto, o conteúdo de umidade apresentou reduções $(p<0,05)$ nos grãos armazenados a $40{ }^{\circ} \mathrm{C}$, em relação ao início do armazenamento, independentemente da coloração do pericarpo dos grãos. As variações no conteúdo de umidade dos grãos se deve ao sistema de armazenamento utilizado, que é o semi-hermético. Esse sistema permite trocas de ar com o ambiente externo de armazenamento. Dessa forma, quando a pressão de vapor de água dos grãos é maior do que a do ar circundante, ocorre o fenômeno de dessorção, e quando a pressão de vapor de água dos grãos é menor que a do ar circundante, ocorre o fenômeno de sorção (SUN; WOODS, 1997), o que explica as alterações que ocorreram nos grãos armazenados, pois os mesmos buscam o equilíbrio higroscópico com o ar circundante. 
Efeitos da temperatura de armazenamento de grãos de arroz integral de pericarpo pardo, preto e vermelho sobre as propriedades físico-químicas e de pasta

Ziegler, $V$. et al.

Tabela 1. Composição proximal de grãos de arroz de pericarpo pardo, preto e vermelho armazenados em quatro temperaturas, no início e após seis meses.

\begin{tabular}{|c|c|c|c|c|c|}
\hline Temperatura $\left({ }^{\circ} \mathbf{C}\right)^{*}$ & Umidade (\%) & Proteína (\%) & Lipídios (\%) & Cinzas (\%) & Carboidratos (\%) \\
\hline \multicolumn{6}{|l|}{ Pardo } \\
\hline Inicial & $13,3 \pm 0,0^{b}$ & $9,3 \pm 0,2^{a}$ & $3,4 \pm 0,2^{a}$ & $1,6 \pm 0,1^{\mathrm{a}}$ & $72,4 \pm 0,2^{b}$ \\
\hline 16 & $14,4 \pm 0,4^{a}$ & $9,1 \pm 0,1^{\mathrm{a}}$ & $3,4 \pm 0,2^{a}$ & $1,6 \pm 0,0^{a}$ & $71,5 \pm 0,7^{b}$ \\
\hline 24 & $15,5 \pm 0,1^{a}$ & $9,0 \pm 0,2^{a}$ & $3,3 \pm 0,1^{a}$ & $1,6 \pm 0,1^{\mathrm{a}}$ & $71,6 \pm 0,3^{b}$ \\
\hline 32 & $13,5 \pm 0,1^{b}$ & $9,0 \pm 0,2^{a}$ & $3,4 \pm 0,1^{a}$ & $1,6 \pm 0,0^{a}$ & $72,5 \pm 0,3^{b}$ \\
\hline 40 & $12,3 \pm 0,2^{c}$ & $9,0 \pm 0,1^{\mathrm{a}}$ & $3,4 \pm 0,1^{\mathrm{a}}$ & $1,6 \pm 0,1^{\mathrm{a}}$ & $73,8 \pm 0,1^{a}$ \\
\hline \multicolumn{6}{|l|}{ Preto } \\
\hline Inicial & $13,7 \pm 0,1^{a}$ & $9,8 \pm 0,4^{a}$ & $4,4 \pm 0,4^{a}$ & $1,7 \pm 0,0^{\mathrm{a}}$ & $70,5 \pm 0,1^{c}$ \\
\hline 16 & $13,6 \pm 0,1^{a}$ & $9,7 \pm 0,1^{a}$ & $4,3 \pm 0,2^{a}$ & $1,7 \pm 0,0^{a}$ & $70,6 \pm 0,3^{c}$ \\
\hline 24 & $13,4 \pm 0,2^{a}$ & $9,7 \pm 0,1^{a}$ & $4,3 \pm 0,3^{a}$ & $1,7 \pm 0,0^{\mathrm{a}}$ & $70,8 \pm 0,4^{c}$ \\
\hline 32 & $12,2 \pm 0,1^{b}$ & $9,6 \pm 0,2^{a}$ & $4,3 \pm 0,1^{a}$ & $1,7 \pm 0,1^{\mathrm{a}}$ & $72,1 \pm 0,1^{b}$ \\
\hline 40 & $11,1 \pm 0,2^{c}$ & $9,5 \pm 0,3^{a}$ & $4,3 \pm 0,3^{a}$ & $1,7 \pm 0,0^{\mathrm{a}}$ & $73,4 \pm 0,1^{a}$ \\
\hline \multicolumn{6}{|l|}{ Vermelho } \\
\hline Inicial & $13,6 \pm 0,0^{a}$ & $9,4 \pm 0,1^{a}$ & $4,4 \pm 0,2^{a}$ & $1,5 \pm 0,1^{\mathrm{a}}$ & $71,0 \pm 0,6^{b}$ \\
\hline 16 & $13,9 \pm 0,2^{a}$ & $9,3 \pm 0,1^{\mathrm{a}}$ & $4,4 \pm 0,2^{a}$ & $1,5 \pm 0,0^{\mathrm{a}}$ & $70,9 \pm 0,3^{b}$ \\
\hline 24 & $13,9 \pm 0,1^{a}$ & $9,2 \pm 0,2^{a}$ & $4,3 \pm 0,1^{a}$ & $1,6 \pm 0,0^{a}$ & $70,9 \pm 0,4^{b}$ \\
\hline 32 & $12,9 \pm 0,1^{b}$ & $9,2 \pm 0,2^{a}$ & $4,3 \pm 0,5^{a}$ & $1,6 \pm 0,1^{\mathrm{a}}$ & $71,9 \pm 0,1^{b}$ \\
\hline 40 & $11,7 \pm 0,3^{c}$ & $9,2 \pm 0,3^{a}$ & $4,3 \pm 0,4^{a}$ & $1,6 \pm 0,0^{a}$ & $73,2 \pm 0,4^{a}$ \\
\hline
\end{tabular}

*Para grãos de arroz de pericarpo pardo, preto e vermelho, médias aritméticas simples de três repetições \pm desvio padrão, seguidas por diferentes letras minúsculas na mesma coluna, diferem entre si pelo teste de Tukey $(p<0,05)$.

Assim, quanto maior a temperatura de armazenamento, menor é a umidade de equilíbrio dos grãos.

O conteúdo de carboidratos apresentou aumento $(p<0,05)$ na temperatura de $40^{\circ} \mathrm{C}$, após seis meses de armazenamento, independentemente da coloração do pericarpo dos grãos. Os carboidratos foram determinados por diferença dos demais constituintes e, dessa forma, a redução da umidade proporciona automaticamente o aumento de carboidratos, conforme verificado em estudo realizado por Gopinger et al. (2015).

\subsection{Propriedades de pasta}

Os resultados obtidos para as propriedades de pasta dos grãos de arroz de pericarpo pardo, preto e vermelho estão apresentados na Tabela 2. No início do armazenamento, a temperatura de pasta foi de $71,7,67,9$ e $75,9{ }^{\circ} \mathrm{C}$, respectivamente, para os grãos com pericarpo pardo, preto e vermelho. Após seis meses de armazenamento, houve um aumento $(p<0,05)$ da temperatura de pasta, principalmente na temperatura de $40{ }^{\circ} \mathrm{C}$. Os aumentos foram de $15,1,9,6$ e 9,2 ${ }^{\circ} \mathrm{C}$, respectivamente, para os grãos com pericarpo pardo, preto e vermelho, em relação ao início do armazenamento. Os resultados encontrados estão de acordo com Silva et al. (2014), que verificaram aumento $(p<0,05)$ na temperatura de pasta em grãos de arroz pardo armazenados em escala industrial, com $12 \%$ de umidade, após nove meses, em temperatura ambiente.

O pico de viscosidade dos grãos com pericarpo pardo armazenados nas temperaturas de 32 e $40^{\circ} \mathrm{C}$ apresentaram, respectivamente, 49,8 e 138,2 RVU de redução $(p<0,05)$ em relação ao início do armazenamento (Tabela 2). Para os grãos com pericarpo vermelho armazenados na temperatura de $40^{\circ} \mathrm{C}$, houve redução $(p<0,05)$ de 81,4 RVU, em relação ao início do armazenamento. Já para os grãos com pericarpo preto, não são observadas alterações ( $p$ 0,05) com o tempo e a temperatura de armazenamento.

Redução significativa $(p<0,05)$ no pico de viscosidade também foi relatada por Sirisoontaralak e Noomhorm (2007) no armazenamento de grãos de arroz com pericarpo pardo, na temperatura de $25^{\circ} \mathrm{C}$, após 12 meses. Da mesma forma, Silva et al. (2014) verificaram redução significativa no pico de viscosidade de grãos de arroz de pericarpo pardo, armazenados com 12\% de umidade, em temperatura ambiente, após nove meses. Na prática, a redução do pico de viscosidade demonstra que se esses grãos forem industrializados como farinha, a viscosidade do gel será menor, o que limita sua aplicação em mingaus, por exemplo.

A viscosidade de quebra (Breakdown) apresentou redução de 113,3 RVU nos grãos com pericarpo pardo, armazenados na temperatura de $40^{\circ} \mathrm{C}$, em relação ao início do armazenamento (Tabela 2). Para os grãos com pericarpo vermelho, observa-se uma redução da viscosidade de quebra de 63,7 RVU, nos grãos armazenados a $40^{\circ} \mathrm{C}$, em relação ao início do armazenamento. Já para os grãos com pericarpo preto, não são verificadas alterações $(p>0,05)$ na viscosidade de quebra em função do tempo e da temperatura de armazenamento. Redução na viscosidade de quebra também foi observada por Park et al. (2012), 
Efeitos da temperatura de armazenamento de grãos de arroz integral de pericarpo pardo, preto e vermelho sobre as propriedades físico-químicas e de pasta

Ziegler, $V$. et al.

Tabela 2. Propriedades de pasta (RVA) de grãos de arroz de pericarpo pardo, preto e vermelho armazenados em quatro temperaturas, no início e após seis meses.

\begin{tabular}{cccccc}
$\begin{array}{c}\text { Temperatura } \\
\left({ }^{\circ} \mathbf{C}\right)^{*}\end{array}$ & $\begin{array}{c}\text { Temperatura de } \\
\left.\text { pasta } \mathbf{~}^{\circ} \mathbf{C}\right)\end{array}$ & $\begin{array}{c}\text { Pico de } \\
\text { viscosidade (RVU) }\end{array}$ & $\begin{array}{c}\text { Breakdown } \\
\text { (RVU) }\end{array}$ & $\begin{array}{c}\text { Viscosidade final } \\
\text { (RVU) }\end{array}$ & $\begin{array}{c}\text { Setback } \\
\text { (RVU) }\end{array}$ \\
$\begin{array}{c}\text { Pardo } \\
\text { Inicial }\end{array}$ & $71,7 \pm 0,1^{\mathrm{d}}$ & $546,2 \pm 1,5^{\mathrm{a}}$ & $141,5 \pm 4,8^{\mathrm{a}}$ & $727,6 \pm 20,9^{\mathrm{b}}$ & $315,4 \pm 0,5^{\mathrm{b}}$ \\
16 & $71,8 \pm 0,1^{\mathrm{d}}$ & $546,3 \pm 3,2^{\mathrm{a}}$ & $145,9 \pm 4,2^{\mathrm{a}}$ & $809,4 \pm 0,9^{\mathrm{a}}$ & $404,0 \pm 8,9^{\mathrm{a}}$ \\
24 & $77,1 \pm 0,5^{\mathrm{c}}$ & $546,9 \pm 3,0^{\mathrm{a}}$ & $141,2 \pm 6,4^{\mathrm{a}}$ & $808,6 \pm 1,1^{\mathrm{a}}$ & $408,8 \pm 2,5^{\mathrm{a}}$ \\
32 & $82,4 \pm 0,1^{\mathrm{b}}$ & $496,4 \pm 3,0^{\mathrm{b}}$ & $96,0 \pm 2,8^{\mathrm{b}}$ & $813,9 \pm 0,5^{\mathrm{a}}$ & $413,4 \pm 5,4^{\mathrm{a}}$ \\
40 & $86,8 \pm 0,6^{\mathrm{a}}$ & $408,0 \pm 2,8^{\mathrm{c}}$ & $28,2 \pm 3,6^{\mathrm{c}}$ & $813,5 \pm 0,4^{\mathrm{a}}$ & $433,4 \pm 13,4^{\mathrm{a}}$ \\
Preto & & & & & \\
Inicial & $67,9 \pm 0,1^{\mathrm{b}}$ & $358,1 \pm 0,4^{\mathrm{a}}$ & $149,6 \pm 4,7^{\mathrm{a}}$ & $433,4 \pm 10,4^{\mathrm{b}}$ & $224,9 \pm 6,1^{\mathrm{c}}$ \\
16 & $68,1 \pm 0,5^{\mathrm{b}}$ & $357,3 \pm 1,1^{\mathrm{a}}$ & $146,5 \pm 2,1^{\mathrm{a}}$ & $447,5 \pm 1,9^{\mathrm{b}}$ & $238,2 \pm 1,3^{\mathrm{bc}}$ \\
24 & $68,5 \pm 0,1^{\mathrm{b}}$ & $369,9 \pm 11,8^{\mathrm{a}}$ & $141,5 \pm 7,5^{\mathrm{a}}$ & $455,4 \pm 4,0^{\mathrm{b}}$ & $238,5 \pm 1,8^{\mathrm{bc}}$ \\
32 & $70,9 \pm 1,1^{\mathrm{b}}$ & $385,1 \pm 14,1^{\mathrm{a}}$ & $154,2 \pm 6,3^{\mathrm{a}}$ & $450,5 \pm 3,2^{\mathrm{b}}$ & $249,5 \pm 0,4^{\mathrm{b}}$ \\
40 & $77,5 \pm 1,1^{\mathrm{a}}$ & $373,2 \pm 3,5^{\mathrm{a}}$ & $146,1 \pm 1,4^{\mathrm{a}}$ & $492,9 \pm 8,3^{\mathrm{a}}$ & $265,7 \pm 6,1^{\mathrm{a}}$ \\
Vermelho & & & & & \\
Inicial & $75,9 \pm 0,1^{\mathrm{d}}$ & $338,9 \pm 16,2^{\mathrm{a}}$ & $98,7 \pm 3,5^{\mathrm{a}}$ & $708,6 \pm 5,2^{\mathrm{a}}$ & $468,3 \pm 17,9^{\mathrm{a}}$ \\
16 & $76,8 \pm 0,1^{\mathrm{cd}}$ & $310,9 \pm 20,3^{\mathrm{a}}$ & $95,4 \pm 4,1^{\mathrm{a}}$ & $632,6 \pm 22,5 \mathrm{~b}^{\mathrm{c}}$ & $421,2 \pm 0,7^{\mathrm{b}}$ \\
24 & $77,5 \pm 0,0^{\mathrm{c}}$ & $309,0 \pm 4,3^{\mathrm{a}}$ & $80,5 \pm 7,3^{\mathrm{b}}$ & $652,4 \pm 11,1^{\mathrm{b}}$ & $423,9 \pm 4,6^{\mathrm{b}}$ \\
32 & $79,0 \pm 0,1^{\mathrm{b}}$ & $311,2 \pm 4,1^{\mathrm{a}}$ & $75,1 \pm 3,9^{\mathrm{b}}$ & $632,5 \pm 10,3 \mathrm{~b}^{\mathrm{c}}$ & $419,5 \pm 2,1^{\mathrm{b}}$ \\
40 & $85,1 \pm 0,5^{\mathrm{a}}$ & $257,5 \pm 5,8^{\mathrm{b}}$ & $35,0 \pm 0,6^{\mathrm{c}}$ & $592,5 \pm 2,7^{\mathrm{c}}$ & $370,0 \pm 3,6^{\mathrm{c}}$ \\
\hline
\end{tabular}

*Para grãos de arroz de pericarpo pardo, preto e vermelho, médias aritméticas simples de três repetições \pm desvio padrão, seguidas por diferentes letras minúsculas na mesma coluna, diferem entre si pelo teste de Tukey $(p<0,05)$.

no armazenamento de grãos de arroz pardo polido, com umidade de $16,5 \%$, na temperatura de $40^{\circ} \mathrm{C}$, após quatro meses de armazenamento. Comportamento similar também foi observado por Sirisoontaralak e Noomhorm (2007) e Silva et al. (2014)

A viscosidade final dos grãos com pericarpo pardo e preto, armazenados na temperatura de $40{ }^{\circ} \mathrm{C}$, aumentou significativamente $(p<0,05)$ em relação ao início do armazenamento, sendo que, para os grãos com pericarpo pardo, o aumento foi de 85,9 RVU, e para os grãos com pericarpo preto, o aumento foi de 59,5 RVU. Já para os grãos com pericarpo vermelho, armazenados por seis meses, na temperatura de $40{ }^{\circ} \mathrm{C}$, observa-se o comportamento contrário, com redução de 116,1 RVU, em relação ao início do armazenamento.

As pesquisas disponíveis na literatura apresentam algumas divergências de resultados em relação à viscosidade final de pasta, no armazenamento de grãos de arroz. Sirisoontaralak e Noomhorm (2007) verificaram aumento $(p<0,05)$ da viscosidade final em grãos de arroz armazenados por 12 meses, na temperatura de $25^{\circ} \mathrm{C}$. Comportamento similar também foi observado por Chen et al. (2015), investigando o armazenamento de arroz Japônico com $12,3 \%$ de umidade, na temperatura de $18^{\circ} \mathrm{C}$, por 15 meses. De acordo com esses autores, o aumento da viscosidade final é atribuído à forte interação entre o amido e a proteína, bem como ao aumento das pontes dissulfeto, com o aumento do tempo e da temperatura de armazenamento, o que provoca também um aumento da retrogradação, como pode ser observado na Tabela 2. Por outro lado, Silva et al. (2014) verificaram redução significativa $(p<0,05)$ da viscosidade final, após nove meses de armazenamento de grãos de arroz pardo, com $12 \%$ de umidade. Essas reduções podem ser explicadas por um maior grau de fragmentação dos polímeros de amido, dificultando a agregação de água em meio à sua estrutura, formando géis com estrutura mais fraca, o que representa menor viscosidade final.

A retrogradação (Setback) dos grãos com pericarpo pardo e preto, armazenados na temperatura de $40{ }^{\circ} \mathrm{C}$, aumentou significativamente $(p<0,05)$ em relação ao início do armazenamento, sendo que, para os grãos com pericarpo pardo, esse aumento foi de 118,0 RVU, e para os grãos com pericarpo preto, o aumento foi de 40,8 RVU. No entanto, para os grãos com pericarpo vermelho, observa-se comportamento contrário, com redução de 98,3 RVU, nos grãos armazenados na temperatura de $40^{\circ} \mathrm{C}$, em relação ao início do armazenamento.

Os dados de retrogradação também apresentam algumas divergências, em estudos realizados com armazenamento de arroz. Park et al. (2012) verificaram aumento significativo $(p<0,05)$ da retrogradação em grãos de arroz de pericarpo pardo polido, armazenamento com $16,5 \%$ de umidade, na temperatura de $40^{\circ} \mathrm{C}$, após quatro meses. Por outro lado, Chen et al. (2015) verificaram redução significativa $(p<0,05)$ da retrogradação em grãos de arroz Japônico, armazenados por 18 meses, com 12,3\% de umidade, na temperatura de $15^{\circ} \mathrm{C}$. Resultado similar 
Efeitos da temperatura de armazenamento de grãos de arroz integral de pericarpo pardo, preto e vermelho sobre as propriedades físico-químicas e de pasta

Ziegler, $V$. et al.

também foi observado por Silva et al. (2014), em estudo com arroz de pericarpo pardo. De acordo com esses autores, a redução da retrogradação está associada com a redução da viscosidade final, observada nos grãos com pericarpo vermelho pela desorganização das estruturas de amido, o que dificulta o seu rearranjo. O aumento da retrogradação, verificado nos grãos com pericarpo pardo e preto, após seis meses de armazenamento, demostra que, se esses grãos forem industrializados como farinha, poderá ocorrer a sinérese (perda de água), o que é indesejado em diversos alimentos.

As alterações nas propriedades de pasta observadas nos grãos moídos são explicadas, geralmente, da seguinte maneira: o aumento da temperatura de pasta ocorre pelo fortalecimento das ligações dissulfídicas entre as moléculas de proteína, após o período de armazenamento, proporcionando uma matriz proteica mais rígida (TANANUWONG; MALILA, 2011) e fortemente aderida à matriz amilácea, além da complexação de ácidos graxos livres com as cadeias de amilose, o que retarda a capacidade de o amido absorver água durante a hidratação, provocando uma redução do pico de viscosidade dos grãos e dificultando o colapso (Breakdown) das estruturas do amido após a formação da pasta.

\subsection{Proteína solúvel}

Os resultados obtidos para a proteína solúvel dos grãos de arroz de pericarpo pardo, preto e vermelho estão apresentados na Figura 1. A proteína predominante no arroz é a orizenina, pertencente à classe das glutelinas, que são solúveis em soluções ácidas e básicas, e que representam cerca de $80 \%$ das proteínas do arroz (MARTIN; FITZGERALD, 2002). No entanto, um estudo da solubilidade proteica em água (albuminas) é importante para se estimarem as interações que ocorrem com essas proteínas durante o armazenamento dos grãos.

No início do armazenamento, a solubilidade proteica em água foi de 8,94, 8,95 e 5,92\%, respectivamente, para os grãos com pericarpo pardo, preto e vermelho. Após seis meses de armazenamento dos grãos, observa-se uma redução $(p<0,05)$ da solubilidade proteica, em todas as condições testadas, independentemente da coloração do pericarpo, sendo que as principais reduções são observadas na temperatura de $40^{\circ} \mathrm{C}$, com $85,5,91,8$ e $80,9 \%$ de redução, respectivamente, para os grãos com pericarpo pardo, preto e vermelho, em relação ao início do armazenamento.

Resultados semelhantes com redução da solubilidade proteica foi observado por Paraginski et al. (2014), durante o armazenamento de grãos de milho com $14 \%$ de umidade, na temperatura de $35^{\circ} \mathrm{C}$, após um período de 12 meses. A elevada redução da solubilidade proteica em água, durante o armazenamento, é resultado da complexação de proteínas com o amido, do fortalecimento das ligações dissulfídicas, da participação de alguns aminoácidos nas reações de Maillard e, ainda, de uma possível desnaturação decorrente da exposição dos grãos à temperatura de $40{ }^{\circ} \mathrm{C}$, durante um período de seis meses (MARTIN; FITZGERALD, 2002).

\section{$3.40 \mathrm{pH}$ dos grãos}

Os resultados obtidos para o pH dos grãos de arroz de pericarpo pardo, preto e vermelho estão apresentados na Figura 2. No início do armazenamento, os grãos de arroz apresentaram $\mathrm{pH}$ próximo da neutralidade, sendo de 6,7, 6,7 e 6,8, respectivamente, para os grãos com pericarpo pardo, preto e vermelho. Após seis meses de armazenamento, houve redução $(p<0,05)$ do $\mathrm{pH}$ dos grãos em todas as condições de armazenamento testadas, sendo que as principais reduções são observadas no armazenamento a $40^{\circ} \mathrm{C}$, chegando a valores de $5,9,5,8$ e 5,9, respectivamente, para os grãos de pericarpo pardo, preto e vermelho.

Reduções do $\mathrm{pH}$ dos grãos também foram verificadas por Paraginski et al. (2014), no armazenamento de grãos de milho com $14 \%$ de umidade, na temperatura de $35^{\circ} \mathrm{C}$,
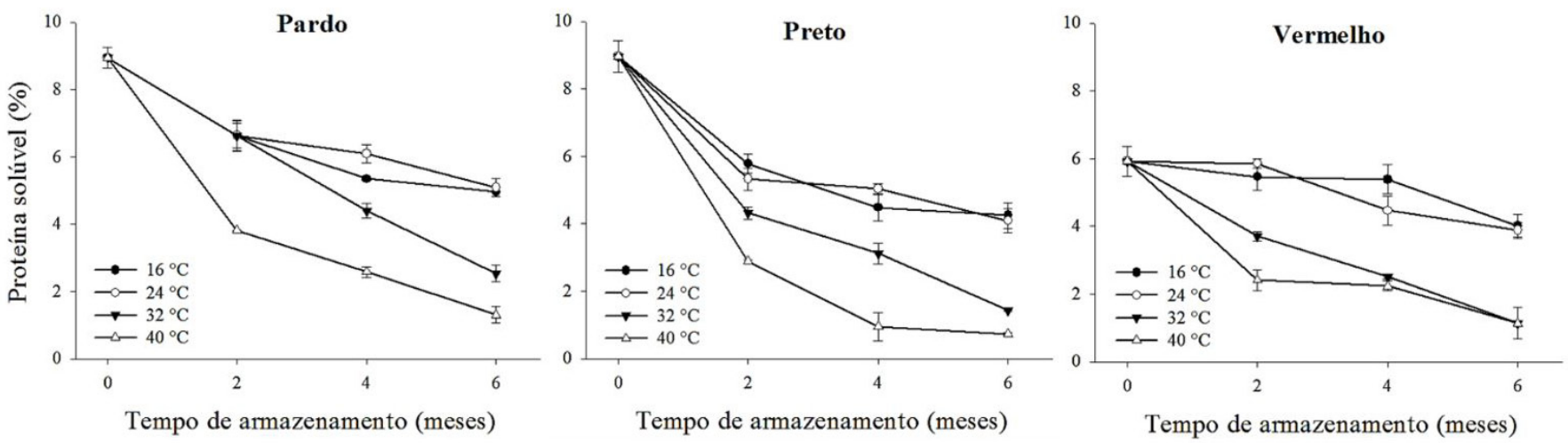

Figura 1. Proteína solúvel de grãos de arroz de pericarpo pardo, preto e vermelho armazenados em quatro temperaturas durante seis meses. 
Ziegler, $V$. et al.
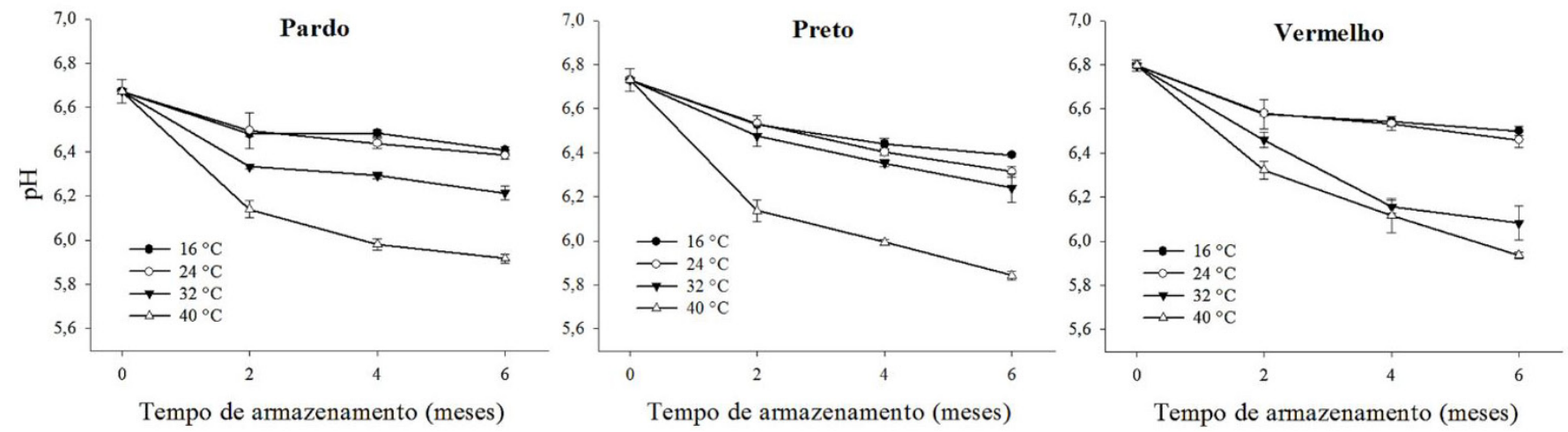

Figura 2. Parâmetro pH dos grãos de arroz de pericarpo pardo, preto e vermelho armazenados em quatro temperaturas durante seis meses.
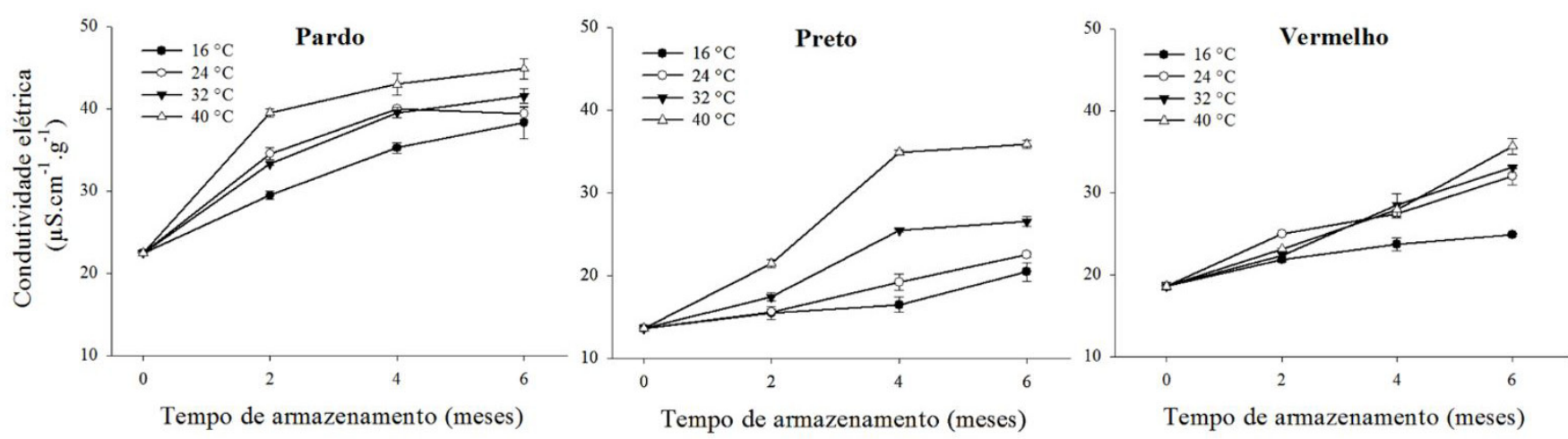

Figura 3. Condutividade elétrica de grãos de arroz de pericarpo pardo, preto e vermelho armazenados em quatro temperaturas durante seis meses.

após 12 meses. Resultados similares também foram observados por Rehman et al. (2002). Para esses autores, a redução do $\mathrm{pH}$ dos grãos é atribuída ao lixiviamento de íons de hidrogênio do interior das células para a solução, o que indica uma maior desestruturação celular dos grãos nessas condições.

\subsection{Condutividade elétrica}

Os resultados obtidos para a condutividade elétrica dos grãos de arroz de pericarpo pardo, preto e vermelho estão apresentados na Figura 3. No início do armazenamento, os grãos de arroz apresentaram uma condutividade elétrica de 22,4, 13,6 e 18,6 $\mu \mathrm{S} . \mathrm{cm}^{-1} . \mathrm{g}^{-1}$, respectivamente, para os grãos com pericarpo pardo, preto e vermelho. Essa variação de condutividade elétrica no início do armazenamento se deve às características da cultivar e das condições de cultivo e de colheita.

Após seis meses de armazenamento, houve incremento $(p<0,05)$ da condutividade elétrica em todas as condições de armazenamento testadas, independentemente da coloração do pericarpo, sendo que os principais aumentos são observados nos grãos armazenados a $40^{\circ} \mathrm{C}$, chegando a valores de 44,8, 35,9 e 35,6 $\mu \mathrm{S} . \mathrm{cm}^{-1} . \mathrm{g}^{-1}$, respectivamente, para os grãos com pericarpo pardo, preto e vermelho.
Por outro lado, os menores incrementos são observados nos grãos armazenados na temperatura de $16{ }^{\circ} \mathrm{C}$.

Incrementos na condutividade elétrica durante o armazenamento de outros grãos foram relatados na literatura. Nasar-Abbas et al. (2008) verificaram aumentos na condutividade elétrica de grãos de Fava armazenados a $50^{\circ} \mathrm{C}$, durante 12 meses. Da mesma forma, Paraginski et al. (2015) verificaram aumentos na condutividade elétrica de grãos de milho, armazenados com 14\% de umidade, na temperatura de $35^{\circ} \mathrm{C}$, após 12 meses.

A determinação de condutividade elétrica é uma medida indireta da integridade celular dos grãos. Com o aumento do tempo e da temperatura de armazenamento dos grãos, a velocidade das reações químicas e enzimáticas é aumentada, proporcionando uma maior desestruturação celular, o que aumenta o lixiviamento de sais, metais e moléculas ácidas, as quais, dissociadas em meio aquoso, passam a conduzir corrente elétrica (COSTA et al., 2010), proporcionando também a redução do $\mathrm{pH}$ dos grãos, conforme verificado na Figura 2. Dessa forma, a utilização de temperatura de refrigeração $\left(16^{\circ} \mathrm{C}\right)$ é indicada para proporcionar uma melhor conservação da integridade celular dos grãos, devido à redução da atividade metabólica. 
Efeitos da temperatura de armazenamento de grãos de arroz integral de pericarpo pardo, preto e vermelho sobre as propriedades físico-químicas e de pasta

Ziegler, $V$. et al.

\section{Conclusões}

Durante o armazenamento dos grãos integrais, independentemente da coloração do pericarpo, as principais alterações são verificadas no armazenamento a $40{ }^{\circ} \mathrm{C}$, durante seis meses, com aumento da temperatura de pasta e redução da solubilidade proteica, sendo que os grãos armazenados em temperaturas mais amenas $\left(16\right.$ a $\left.24^{\circ} \mathrm{C}\right)$ apresentaram as menores alterações. $\mathrm{O}$ armazenamento a $40^{\circ} \mathrm{C}$, durante 6 meses, proporcionou reduções no $\mathrm{pH}$ dos grãos e aumento da condutividade elétrica, devido a uma maior desestruturação celular. Esses resultados representam que o armazenamento em temperaturas na faixa de 32 a $40{ }^{\circ} \mathrm{C}$ provocam reduções na qualidade culinária e de cocção desses grãos, o que poderá ser facilmente percebido pelos consumidores. Dessa forma, o armazenamento de grãos de arroz com pericarpo pardo, preto e vermelho na temperatura de $16^{\circ} \mathrm{C}$ é o mais indicado para a redução da atividade metabólica e enzimática, proporcionando as mínimas alterações nas propriedades físico-químicas e de pasta.

\section{Agradecimentos}

Gostaríamos de agradecer à MPB agroindústria pelo fornecimento das amostras, à CAPES, ao CNPQ, à SCT-RS e ao Polo de Inovação Tecnológica em Alimentos da Região Sul.

\section{Referências}

AGUIAR, R. W. S.; BRITO, D. R.; OOTANI, M. A.; FIDELIS, R. R.; PELUZIO, J. N. Efeito do dióxido do carbono, temperatura e armazenamento sobre sementes de soja e micoflora associada. Revista Ciência Agronômica, Fortaleza, v. 43, n. 3, p. 554-560, 2012. http://dx.doi.org/10.1590/S1806-66902012000300019.

AMERICAN ASSOCIATION OF CEREAL CHEMISTS - AACC. Approved methods of the American Association of Cereal Chemists. St. Paul, 1995.

AMERICAN SOCIETY OF AGRICULTURAL ENGINEERS - ASAE. Moisture measurement unground grain and seeds. St. Joseph, 2000. 563 p.

CHEN, Y.; JIANG, W.; JIANG, Z.; CHEN, X.; CAO, J.; DONG, W.; DAI, B. Changes in physicochemical, structural, and sensory properties of irradiated brown Japonica rice during storage. Journal of Agriculture and Food Chemistry, Washington, v. 63, n. 17, p. 4361-4369, 2015. PMid:25879171. http://dx.doi. org/10.1021/jf5047514.

COMPANHIA NACIONAL DE ABASTECIMENTO - CONAB. Acompanhamento da safra brasileira de grãos: décimo levantamento. Brasília, 2015. Disponível em: <http://www.conab. gov.br/OlalaCMS/uploads/arquivos/15_07_09_08_59_32_boletim_ graos_julho_2015.pdf>. Acesso em: 11 abr. 2016.
COSTA, A. R.; FARONI, L. R. D.; ALENCAR, E. R.; CARVALHO, M. C. S.; FERREIRA, L. G. Qualidade de grãos de milho armazenados em silos bolsa. Revista Ciência Agronômica, Fortaleza, v. 41, n. 2, p. 200-207, 2010. http://dx.doi.org/10.1590/ S1806-66902010000200005.

ELIAS, M. C.; OLIVEIRA, M.; VANIER, N. L.; PARAGINSKI, R. T.; CASARIL, J. Manejo tecnológico na pós-colheita e inovações na conservação de grãos de arroz. In: ELIAS, M. C.; OLIVEIRA, M.; VANIER, N. L. (Ed.). Qualidade de arroz da pós-colheita ao consumo. Pelotas: Editora Universitária da UFPel, 2012. v. 1, p. 21-42.

FINOCCHIARO, F.; FERRARI, B.; GIANINETTI, A. A study of biodiversity of flavonoid content in the rice caryopsis evidencing simultaneous accumulation of anthocyanins and proanthocyanidins in a black-grained genotype. Journal of Cereal Science, London, v. 51, n. 1, p. 28-34, 2010. http://dx.doi.org/10.1016/j. jcs.2009.09.003.

GOPINGER, E.; ZIEGLER, V.; CATALAN, A. A. S.; KRABBE, E. L.; ELIAS, M. C.; XAVIER, E. G. Whole rice bran stabilization using a short chain organic acid mixture. Journal of Stored Products Research, Manhattan, v. 61, n. 1, p. 108-113, 2015. http://dx.doi.org/10.1016/j.jspr.2015.01.003.

GUNARATNE, A.; WU, K.; LI, D.; BENTOTA, A.; CORKE, H.; CAI, Y. Antioxidant activity and nutritional quality of traditional red-grained rice varieties containing proanthocyanidins. Food Chemistry, Whiteknights, v. 138, n. 2-3, p. 1153-1161, 2013. PMid:23411226. http://dx.doi.org/10.1016/j.foodchem.2012.11.129.

HEINEMANN, R. J. B.; FAGUNDES, P. L.; PINTO, E. A.; PENTEADO, M. V. C.; LANFER-MARQUEZ, U. M. Comparative study of nutrient composition of commercial brown, parboiled and milled rice from Brazil. Journal of Food Composition and Analysis, New York, v. 18, n. 4, p. 287-296, 2005. http://dx.doi.org/10.1016/j. jfca.2004.07.005.

INTERNATIONAL SEED TESTING ASSOCIATION - ISTA. Determination of other seeds by number. In: International rules for seed testing. Bassersdorf, 2008. p. 4.1-4.3.

LIU, K.; MCWATTERS, K. H.; PHILLIPS, R. D. Protein insolubilization and thermal destabilization during storage as related to hardto-cook defect in cowpeast. Journal of Agriculture and Food Chemistry, Washington, v. 40, n. 1, p. 2403-2407, 1992.

MARTIN, M.; FITZGERALD, M. A. Proteins in rice grains influence cooking properties. Journal of Cereal Science, London, v. 36, n. 3, p. 285-294, 2002. http://dx.doi.org/10.1006/jcrs.2001.0465.

MONKS, J. F.; VANIER, N. L.; CASARIL, J.; BERTO, R. M.; OLIVEIRA, M.; GOMES, C. B.; CARVALHO, M. P.; DIAS, A. R. G.; ELIAS, M. C. Effects of milling on proximate composition, folic acid, fatty acids and technological properties of rice. Journal of Food Composition and Analysis, New York, v. 30, n. 2, p. 73-79, 2013. http://dx.doi.org/10.1016/j.jfca.2013.01.009. 
Efeitos da temperatura de armazenamento de grãos de arroz integral de pericarpo pardo, preto e vermelho sobre as propriedades físico-químicas e de pasta

Ziegler, $V$. et al.

NASAR-ABBAS, S. M.; PLUMMER, J. A.; SIDDIQUE, K. H. M.; WHITE, P.; HARRIS, D.; DODS, K. Cooking quality of faba bean after storage at high temperature and the role of lignins and other phenolics in bean hardening. LWT - Food Science and Technology, London, v. 41, n. 7, p. 1260-1267, 2008.

PAIVA, F. F.; VANIER, N. L.; BERRIOS, J. J.; PAN, J.; VILLANOVA, F. A.; TAKEOKA, G.; ELIAS, M. C. Physicochemical and nutritional properties of pigmented rice subjected to different degrees of milling. Journal of Food Composition and Analysis, New York, v. 35, n. 1, p. 10-17, 2014. http://dx.doi.org/10.1016/j. jfca.2014.05.003.

PARAGINSKI, R. T.; VANIER, N. L.; BERRIOS, J. D. J.; DE OLIVEIRA, M.; ELIAS, M. C. Qualidade de grãos de milho armazenados em diferentes temperaturas. Revista Brasileira de Engenharia Agrícola e Ambiental, Campina Grande, v. 19, n. 4, p. 358-363, 2015. http://dx.doi.org/10.1590/1807-1929/ agriambi.v19n4p358-363.

PARAGINSKI, R. T.; VANIER, N. L.; BERRIOS, J. J.; OLIVEIRA, M.; ELIAS, M. C. Physicochemical and pasting properties of maize as affected by storage temperature. Journal of Stored Products Research, Manhattan, v. 59, n. 1, p. 209-214, 2014. http://dx.doi.org/10.1016/j.jspr.2014.02.010.

PARK, C.; KIM, Y.; PARK, K.; KIM, B. Changes in physicochemical characteristics of rice during storage at different temperatures. Journal of Stored Products Research, Manhattan, v. 48, n. 1, p. 25-29, 2012. http://dx.doi.org/10.1016/j.jspr.2011.08.005.

PEREZ-GARCIA, F.; GONZALEZ-BENITO, M. E. Seed germination of five Helianthemum species: effect of temperature and presowing treatments. Journal of Arid Environments, Madrid, v. 65, n. 1, p. 688-693, 2006. http://dx.doi.org/10.1016/j.jaridenv.2005.10.008.

REHMAN, Z.; HABIB, F.; ZAFAR, S. Nutritional changes in maize (Zea mays) during storage at three temperatures. Food Chemistry, Whiteknights, v. 77, n. 2, p. 197-201, 2002. http:// dx.doi.org/10.1016/S0308-8146(01)00337-5.

SANTOS, C. M. R.; MENEZES, N. L.; VILLELA, F. A. Alterações fisiológicas e bioquímicas em sementes de feijão envelhecidas artificialmente. Revista Brasileira de Sementes, Londrina, v. 26, n. 1, p. 110-119, 2004. http://dx.doi.org/10.1590/S010131222004000100017

SILVA, W. S.; VANIER, N. L.; ZIEGLER, V.; OLIVEIRA, M.; DIAS, A. R. G.; ELIAS, M. C. Effects of using eolic exhausters as a complement to conventional aeration on the quality of rice stored in metal silos. Journal of Stored Products Research, Manhattan, v. 59, n. 1, p. 76-81, 2014. http://dx.doi.org/10.1016/j. jspr.2014.05.006.

SINGH, N.; SINGH SANDHU, K.; KAUR, M. Characterization of starches separated from Indian chickpea (Cicer arietinum L.) cultivars. Journal of Food Engineering, Califórnia, v. 63, n. 4, p. 441-449, 2004. http://dx.doi.org/10.1016/j.jfoodeng.2003.09.003.

SIRISOONTARALAK, P.; NOOMHORM, A. Changes in physicochemical and sensory-properties of irradiated rice during storage. Journal of Stored Products Research, Manhattan, v. 43, n. 1, p. 282-289, 2007. http://dx.doi.org/10.1016/j.jspr.2006.06.008.

SOMPONG, R.; SIEBENHANDL-EHN, S.; LINSBERGER-MARTIN, G.; BERGHOFER, E. Physicochemical and antioxidative properties of red and black rice varieties from Thailand, China and Sri Lanka. Food Chemistry, Whiteknights, v. 124, n. 1, p. 132-140, 2011. http://dx.doi.org/10.1016/j.foodchem.2010.05.115.

SUN, D.; WOODS, J. L. Low temperature moisture transfer characteristics of barley: thin-layer models and equilibrium isotherms. Journal of Agricultural Engineering Research, Harpenden, v. 59, n. 4, p. 273-283, 1997. http://dx.doi.org/10.1006/ jaer.1994.1086.

TANANUWONG, K.; MALILA, Y. Changes in physicochemical properties of organic hulled rice during storage under different conditions. Food Chemistry, Whiteknights, v. 125, n. 1, p. 179-185, 2011. http://dx.doi.org/10.1016/j.foodchem.2010.08.057.

WEI, C.; KWON, O. Y.; LIU, X.; KIM, H. C.; YOO, W. K.; KIM, H. M.; KIM, M. R. Protein profiles of major Korean rice cultivars. Journal of Food Science and Nutrition, Hyderabad, v. 12, n. 1, p. 103-110, 2007.

ZHOU, Z.; CHEN, X.; ZHANG, M.; BLANCHARD, C. Phenolics, flavonoids, proanthocyanidin and antioxidant activity of brown rice with different pericarp colors following storage. Journal of Stored Products Research, Manhattan, v. 59, n. 1, p. 120-125, 2014. http://dx.doi.org/10.1016/j.jspr.2014.06.009.

ZIEGLER, V.; FERREIRA, C. D.; GOEBEL, J. T. S.; BATISTA, A.; KRONING, D.; ELIAS, M. C. Efeitos da temperatura de armazenamento sobre as propriedades tecnológicas e sensoriais de arroz integral de pericarpo pardo, preto e vermelho. Brazilian Jounal of Food Research Campo, Mourão, v. 7, n. 3, p. 173-189, 2016. http://dx.doi.org/10.3895/rebrapa.v7n3.4013. 